\title{
Studies on the Change Mechanism of RMB Exchange Rate with Non-Recurrent Events
}

\author{
Rulu Huang \\ F5-524 Xiamen University \\ Siming Street 422, Xiamen City \\ Fujian Province, China \\ E-mail: hrl0816@gmail.com
}

Received: August 8, 2011

Accepted: November 9, $2011 \quad$ Published: January 5, 2012

doi:10.5430/ijfr.v3n1p49

URL: http://dx.doi.org/10.5430/ijfr.v3n1p49

\begin{abstract}
The objectives of this paper are to explore the relationship between the macroeconomic indicators and exchange rate interval, as well as to probe how the government intervention or hot money inflow causes the exchange rate to jump. According to the literature, the RMB exchange rate is affected by the active management of government and the external environment. Therefore, this paper introduces a mathematical model combined with tendency approach and real options with jumping fluctuation to obtain the appropriate RMB exchange rate interval. Firstly, this paper selected the major macroeconomic variables influencing RMB exchange rate by Pearson correlation analysis and tendency approach to observe the relationship between the macroeconomic variables and exchange rate in normal economic condition. In addition, through real options approach we can understand how the central bank intervenes the exchange rate refer to the potential value of decision-making which makes the exchange rate change jumpily. In the process of empirical test, I choose the RMB exchange rate against U.S. dollar as the dependent variable for the reason of the complex interaction between these two economies. Regardless of data insufficiency, the research results in this model in some way demonstrate a proper RMB exchange rate interval which can act as a reference for government authorities making decisions about implementation of economic policies and other thinking of the relationship between economic policies and exchange rate in the future.
\end{abstract}

Keyword: RMB Exchange Rate, Government Intervention, Option Pricing Approach

\section{Introduction}

\subsection{Research Background and Motivation}

Since the world is flat and China has become the world's factory, the RMB exchange rate, which has the biggest impact on the international trading, has also become the major issue of debates. In recent years, the argument about whether or not the RMB exchange rate is reasonable has been ceaseless. A number of economists considered the RMB exchange rate unreasonable due to economic conditions such as high economic growth, continuous foreign trade surplus, increase of foreign direct investment, and people's optimistic expectations. Besides, some scholars believe that the economic conditions in China, along with current unexpected events such as government interventions, WTO accession, the change of exchange rate mechanism, the financial crisis, and the gigantic flow of hot money could drive the RMB exchange rate to jump and distort economic development.

After the financial crisis in 2008, the debate about the exchange rate has become more intense. Although our government has frequently announced that the exchange rate is very close to equilibrium, there are still some opposite opinions. Many people have claimed that the RMB exchange rate is too undervalued, which creates the world trade imbalance. They are dissatisfied about the present level and want to force the currency to appreciate substantially. Based on discussion above, Chinese currency seems to be improperly valued and has appreciated too slowly. Therefore, this study explores how the non-recurrent events affect the RMB exchange rate.

\subsection{Research Purpose and Problem}

In the past decade, there has been growing importance placed on research of the Chinese currency. People are curious about the reasonable exchange rate because they want to examine whether or not the timing of economic policy implementation is suitable. Many scholars have put forward their viewpoints and theories such as purchasing power 
parity (PPP), uncovered interest rate parity and Big Mac Index, as well as other international financial theories with regression or fundamental equilibrium real exchange rate analysis.

However, some issues are also necessary to be regarded. Exchange rates may not change smoothly when sudden events occur, especially for countries with a high degree of internationalization. It means that exchange rates may not always be continues. Although some scholars have noticed this jumping characteristic of exchange rates and analyzed it, they have still ignored the potential value of active management by stakeholders. Stakeholders decide whether or not to executive their strategies when the sudden events occur. Therefore, in consideration of a normal macroeconomic environment and non-recurrent conditions, this study introduces a mathematical model combined with tendency approach and real options with jumping fluctuation to obtain the appropriate RMB exchange rate interval.

\section{Literature Review}

\subsection{Academic Debate of RMB Exchange Rate}

In recent years, many scholars have pointed out that the Chinese currency faces the pressure of appreciation, resulting from continuous foreign trade surplus, accumulated foreign exchange reserves, rapid economic growth, high domestic savings (McKinnon, 2005), and people's optimistic expectations in China. Through economic theories, many scholars and foreign investors supposed that Chinese currency is deeply undervalued.

However, other scholars have suggested that there is no need to adjust the present level of RMB exchange rate. They claimed that RMB was very close to the equilibrium of a real exchange rate (Do and Yang, Goh and Kim). Moreover, influenced by the financial crisis and globe economic recession in 2008, Chinese trading surplus has dropped heavily, resulting less pressure on the appreciation. Therefore, there was no evidence that the Chinese currency was undervalued through a consideration of balance of international payments.

Nowadays, Chinese economy is facing a couple of problems ranging from continuous high inflation rate to scarcity of motivation for economic development. As the tight monetary policy has been implemented to fight against economic bubble, capital market and security market are gradually contracting and fluctuating. So another argument suggests that Chinese currency may have been overvalued now. Meanwhile, the obstacles to Chinese economic development, reduction in real interest rate, shrinking assets in the stock and real estate markets and expected capital loss put pressure on the currency to depreciate.

\subsection{Factors Affecting the RMB Exchange Rate}

From now on, there are no definite conclusions about the factors affecting the exchange rate. According to international finance theory, the balance of international payments, economic growth rate, government controls, money supply, preference of products, productivity level, and expectation affect exchange rates. Especially the PPP, the interest rate parity and the international fisher effect built up the relationship among the inflation rate, interest rate and exchange rate.

In addition, other factors considered by some scholars include government consumption, tariffs (Edward, 1989), growth rate of GDP, foreign exchange reserves, ratio of the volume of imports and exports to GDP, net foreign assets (Clark and MacDonald, 2004), international environment and relationship, etc.

In this study, the above factors will be taken as the variables to estimate the relationship between macroeconomics and exchange rate.

\subsection{Real Options Approach}

According to studies mentioned above, I try to estimate the equilibrium of exchange rates though it's impossible to reflect the fact exactly. A number of approaches have been applied to construct models, such as OLS and panel regression. However, exchange rates do not always move so smoothly (Bo, Wang and Yang, 2010). They are affected by the potential value of government intervention strategies. This study attempts to use real option approach to find the optimal intervention strategy when non-current events happen.

Some scholars have proposed the continuous-time volatility model, which was composed of smooth diffusion and jump component to explain the spot exchange rate. They found the risk premium of jumps in exchange rate is an important part which the traditional diffusion model didn't indicate. However, they only mention the relationship between the forward exchange rate and spot exchange rate. They didn't discuss a lot about what factors would influence the exchange rate.

In 2009, some economists used real options to construct a mathematical model under a managed floating regime (Castellano, Cerqueti and D'Ecclesia). They thought that the exchange rate moved depending on two things, current fundamentals and expectations of future value of exchange rate. In addition, they used the optimal control strategy to 
minimize the cost of difference between the exchange rate and the target. They stated that government interventions incorporate temporary market reactions and make the exchange rate jump away from the target.

\subsection{Government Intervention and Hot Money in China}

The foreign reserve and the credit condition are often seen as the tools for central bank to intervene the foreign exchange market (Beine, Lahaye, Laurent, Neely, and Palm, 2007). The motivation of holding foreign exchange reserve is precautionary for sudden shocks from international market. Recently, many observers are interesting in the rapid accumulation of foreign exchange reserves in China. They think the huge trade surplus and hot money inflow are the driving forces behind the rapid accumulation of foreign exchange reserves.

After the Asian financial crisis in 1997, every government noticed the importance of hot money. Hot money refers to the money which is moved quickly from one country to another to take speculative benefits. Many scholars thought the hot money inflow energizes the Chinese financial system due to financial liberalization, optimistic expectation and interest rate differences (Prasad, Rumbaugh, and Wang, 2005). After the subprime mortgage crisis, a huge amount of hot money flowed into China and Chinese authorities made efforts to stabilize the exchange rate on many occasions.

\section{Model Construction and Analysis}

\subsection{The Long-term Model}

This study assumes that the exchange rate is influenced by normal economic environment and non-recurrent events. Therefore, two different methods were combined to explore the reasonable exchange rate interval. This study established a tendency model which is measured by the regression approach based on the macroeconomic factors in order to understand how the RMB exchange rate is affected by different economic conditions. Next, non-recurrent events like macroeconomic policies and the global economic situation may cause the exchange rate to jump. Therefore, this study also considers the influences of non-recurrent events by using the real options approach to set up a mathematic model.

After the collapse of the Bretton Woods system, the floating exchange rate system has replaced the fixed exchange rate system. China, which uses the managed floating exchange rate system, intervenes in the exchange rate market to stabilize the exchange rate, especially when sudden events occur, just like the open market operations. That is why this study takes government intervention as the factors that influence the effects of non-recurrent events on the exchange rate.

The data in this chapter is annual data derived from the annual reports published by the China's National Statistical Bureau from 1996 to 2009.

\subsection{The Evaluation of Normal Conditions in the Model}

Under normal international trade, the normal economic environment, which is measured by many macroeconomic indicators, significantly impacts the exchange rate. According to international finance theory and relevant literature, this chapter selected some macroeconomic variables which may affect the exchange rate: foreign direct investment (FDIV), trade surplus (TSV), foreign exchange reserves (FERV), unemployment rate (URV), inflation rate (IRV), the shanghai composite stock price index (SPIV), saving rate (SRV), money supply (MSV), domestic industrial output (DIOV), national finance (NFV), GDP, interest rate of one-year deposit (IRDV), and the degree of dependence on exports (DDEV). Since different indicators are recorded by different measurement units, I decided to modify those indicators into their growth rate.

As the "world factory", the industrial output in China is in a larger proportion of economic output. It influences the economic growth a lot. That's the reason to select the domestic industrial output. The other selections are based on the previous literatures.

The analysis was conducted using the SPSS 19.0 statistical software package. First, the correlations among these variables were computed in order to get some possible combinations excluded from the collinearity problem. If the correlation coefficient between two variables is greater than 0.7 , this paper will choose only one variable. The results of correlation are shown in Table 1.

Next, to select the combinations that could represented the normal economic condition, a multiple regression analysis was done. This study took the growth rate of the exchange rate as the dependent variable and the growth rates of macroeconomic indicators as the independent variables for multiple regression analysis. The $\mathrm{R}$ square of the regression model with the following independent variables was the biggest without the collinearity problem. The following eight variables were taken as independent variables: FDIV, TSV, URV, NFV, SPIV, SRV, MSV, and DDEV. The regression results and VIF values are presented in Table 2 and3.3. 
Second, to clarify the relative contributions of these variables, the concept of relative weight was involved. In Table 4 the relative weight of each macroeconomic variable was given as the ratio of the standardized $\beta$ value of each macroeconomic to the sum. It represented the magnitude at each macroeconomic variable influenced the exchange rate. Moreover, this paper took the standardized $\beta$ value as the direction at which macroeconomic variable influenced the exchange rate. As a result, this chapter classified the URV, MSV, DDEV, and NFV into the variables which have positive effects on the growth rate of the exchange rate. Whereas, the TSV, SPIV, SRV, and FDIV were classified into the variables with negative ones.

Each weighted sum was measured from the sum of each macroeconomic variable multiplied respective weight value. Because of RMB exchange rate is quoted by indirect method, the currency should appreciate when the value of variables with positive effects decreases or the value of variables with negative effects increases. Therefore, suppose the weighted minimum sum of the variables with positive effects subtracts the weighted maximum sum of the variables with negative effects is the maximum magnitude of appreciation, the same as the weighted maximum one.

When calculating the magnitude of the influences of these variables on the growth rate of exchange rate, the weighted sum of the averages of the variables which have positive effects on the growth rate of exchange rate plus the weighted sum of the averages of the variables which have negative effects on the growth rate of exchange rate should be zero because the total magnitude of appreciation should equal that ofdepreciation. Thus, I give a multiplier to adjust the magnitude of depreciation in order to match with the magnitude of appreciation. In addition, to avoid the problem of different measurement standard, Table 7 standardizes the total magnitude of appreciation and depreciation. The standardized values are 0.7662 and -0.6427 respectively. This means that the distance from the magnitude by which the RMB exchange rate is 0.7662 standard deviations at most, while the distance from the magnitude by which the RMB exchange rate is 0.6451 standard deviations at most.

The average of the growth rate of the RMB exchange rate is -0.01395 and the standard deviation of the growth rate of exchange rate is 0.0249 from 1996 to 2009. From the above model, we can know that the distance from the magnitude by which the currency should be depreciated to the growth rate of the average RMB exchange rate is 0.5184 standard deviations at most, while the appreciated one is 0.8551 standard deviations at most. Therefore, the reasonable predicted interval of the growth rate of the RMB exchange rate is from -0.035 to -0.001 . Then, this paper does the empirical analysis for the above-mentioned estimated results: the average of the RMB exchange rate from 1996 to 2009 is 8.0065.Finally, the predicted RMB exchange rate interval under normal conditions ranged from 7.273 to 8.314 during these 14 years.

However, the real RMB exchange rate interval was from 6.831 to 8.314 from 1996 to 2009. The difference between the predicted exchange rate interval and real exchange rate interval showed the macroeconomic indicators of China economy seem not to fully explain the exchange rate. The reason may be the external pressure and irrational expectation. The appreciating pressure from western countries, high inflation and interest rate makes Chinese government consider the choice of adjusting the exchange rate to solve these problems. I suppose that irrational expectation and non-fundamental macroeconomic shocks can create the volatility of exchange rate which can be released by policies.

\subsection{The Evaluation of Non-Recurrent Events in the Model}

Nowadays, the exchange rate changes rapidly when non-recurrent events occur. The non-recurrent events which are evaluated by the real options with the jumping fluctuation in this paper can be divided into two parts. One is the real government intervention, which means the government adjusts foreign exchange reserves to intervene in the exchange rate. The other is the potential government intervention, which means the potential value of the exchange rate intervention that the government is waiting for.

The major variable of this real options model is foreign exchange reserves $\left(F_{t}\right)$. Suppose $F_{t}$ followsarithmetic Brownian motion (ABM) with drift $\boldsymbol{a}$ and volatility $\boldsymbol{v}$. When a non-recurrent event q occurs, $F_{t}$ jumps by an amount $\xi$. The process $F_{t}$ that containsboth continuous and discontinuous changes is as follows:

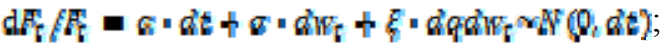 \\ dq $=$ fo whth probability ids: 6 with probabilly 1 - idt}

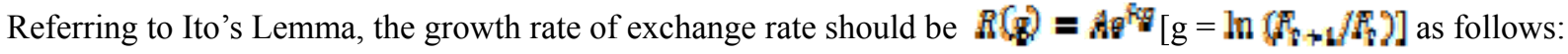

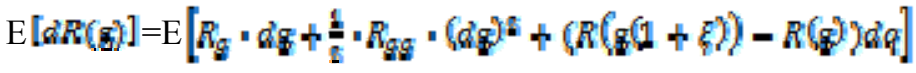




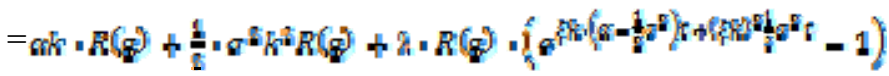

The first-order and second-order differentials of $R(g)$ are presented by $R_{g}$ and $R_{g g}$. After calculating the coefficient $k$ by using the risk-neutral condition, the following equation is satisfied:
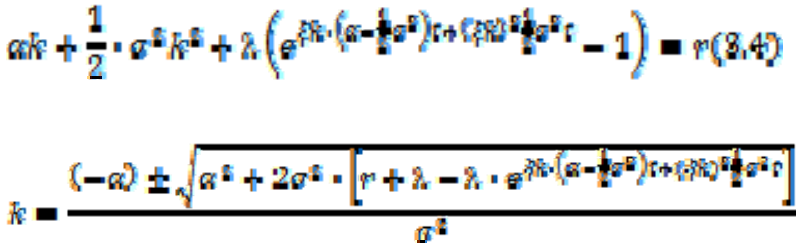

Then,

\subsubsection{The Threshold of Decision in the Model}

Since the government always employs the foreign reserve to intervene without hurting the country's economic strength, the government is very sensitive to the normal economic conditions and the potential advantages of exchange rate differences. Suppose how much the real government intervention will be carried out depends on the normal conditions and the potential government intervention. Based on the value-matching condition and smooth-pasting condition advocated by Dixit and Pindyck, we can calculate the optimal $F_{t}$ and the optimal growth rate of exchange rate as follows:

The value-matching condition and smooth-pasting condition of depreciation:

$$
\begin{aligned}
& a_{1} g_{2}+b_{1}=\mathbb{B}_{2}+A_{1} e^{\hat{k}_{1} g_{1}} \text { (3.6) } \\
& a_{1}=A_{1} F_{1} \oplus^{R_{1} S_{1}} \text { (3.7) }
\end{aligned}
$$

The value-matching condition and smooth-pasting condition of appreciation:

$$
\begin{aligned}
& a_{2} g_{2}+b_{2}=R_{a}^{0}+A_{2} \epsilon^{k_{2} g_{2}}(3.6) \\
& a_{2}=A_{2} k_{2} e^{k_{2} g_{2}}(3.7)
\end{aligned}
$$

$a_{1} \delta_{1}+b_{12}, a_{2} g_{2}+b_{g}$ are real values of government intervention. $R_{2}, R_{2}$ are the influences of macro-economicvariables from above regression. $A_{1} \theta^{8 / 21}, A_{2} e^{k_{3}} g:$ are potential values of government intervention.

\subsubsection{The Numerical Analysis in the Model}

Numerical analysis was conducted based on the above equations with the base parameters shown in Table 8 . The result show that the optimal range of accumulated foreign reserve is from $\$ 746.8093$ to $\$ 1,835.269$ billion, and the optimal RMB exchange rate interval is from 7.012 to 8.314 from 1996 to 2009 .

However, the real accumulated foreign reserve was $\$ 1,946.03$ billion and the real exchange rate was 6.831 in 2009. The excessive accumulated foreign reserve made the exchange rate appreciate faster than we expected. This means that the government did not intervene in the exchange rate appropriately. Some scholars are convinced that the reason for this is hot money, which means that the accumulated foreign reserve cannot be fully commanded by the government because of the relaxed restrictions on capital flows in China. It is possible that the vicious circle under which China submitted to international pressure caused speculative money to spin out of control.

\section{Conclusion}

At the beginning, this study used Pearson correlation analysis to explore the correlation among variables and employed tendency approach to select macroeconomic variables without collinearity as the represents of normal economic conditions. Then, the weighted sums of these variables were measured to predict the appropriate interval of exchange rate from 1996 to 2009. The difference between the prediction and the fact showed the external pressure and irrational expectation make the exchange rate misaligned from the macroeconomic indicators.

In addition, non-recurrent events always induce jumping changes and potential values of growth rate of the exchange rate. This study evaluates them by using real options with jumping fluctuation. However, the predicted results are different from the real exchange rate intervals because the external pressure, irrational expectation and unexpected hot money inflows which distort the government intervention. On one side, the government should improve the institutions of hot money inflow to prevent the chaos in capital market and make government intervention more efficiently. On the other side, the government should also strengthen the national economy through the variables mentioned above to make the exchange rate closer to the real economy. 


\section{References}

Andersen, T., Francis, X. D. \& Clara, V. (2003). Micro effects of macro announcement: Real-time price discovery in foreign exchange. The American Economic Review, 93(1), 38-62.

Beine, M. Lahaye, J., Laurent, S., Neely, C. J. \& Palm, F. C. (2007). Central bank intervention \& exchange rate volatility, its continues\& jump components. International Journal of Finance \& Economics, 12(2), 201-223.

Bo, L., Wang, Y. \&Yang, X. (2010).Markov-modulated jump diffusions for currency option pricing. Insurance: Mathematics \& Economics, 46(3), 461-469

Bouakez, H. \& Normandin, M. (2010). Fluctuations in the foreign exchange market: How important are monetary policy shocks? Journal of International Economics, 81(1), 139-153

Cai, H. M. (2008). What is the RMB exchange rate in 2008? Journal of Economic Outlook, 115(1), 57-74

Cheung, Y, W., \&Qian, X. W. (2010). Capital flight: China's experience. Review of Development Economics, 14(2), 277-247.

Cline, W. R. (2009). 2009 estimates of fundamental equilibrium exchange rates (Policy Brief No.09-10). Washington: Peterson Institute for International Economics.

Kercheval, A. N. \& Moreno, J. F. (2009).Optimal impulse control in currency markets when interventions affect rates.Joint Mathematics Meetings, Washington.

Shen, J. (2008). The invisible h\& dominates the devaluation of RMB. Washington Observer Weekly, 48(1), 21-27.

$\mathrm{Xu}$, J. (2010). Noise traders, exchange rate disconnect puzzle, \& the Tobin tax. Journal of International Money \& Finance, 29(2), 336-357.

Clark, P. B. \& MacDonald, R. (2004).Filtering the BEER: A permanent \& transitory decomposition. Global Finance Journal, 15(1), 29-56

Edwards, S. (1989). Real exchange rates, devaluation \& adjustment: Exchange rate policy in developing countries. MA: MIT Press.

Goh, M. H. \& Kim, Y. (2006).China's exchange rate policy dilemma. American Economic Review, 96(2), 422-426

Table 1. The pearson correlation analysis results

\begin{tabular}{|l|r|r|r|r|r|r|r|r|r|r|r|r|r|r|}
\hline & EXR & FDIV & TSV & FERV & URV & NFV & SPIV & SRV & MSV & DIOV & IRV & GDPV & IRDV & DDEV \\
\hline EXR & 1 & -.066 & -.122 & -.167 & .144 & -.302 & .030 & .010 & -.089 & -.260 & -.406 & -.444 & -.252 & -.535 \\
\hline FDIV & -.066 & 1 & .484 & .426 & -.162 & .390 & .102 & .552 & -.036 & .378 & $.763^{* *}$ & $.621^{*}$ & $.767^{* *}$ & -.177 \\
\hline TSV & -.122 & .484 & 1 & .450 & -.264 & .138 & .011 & .414 & -.024 & .475 & .443 & $.588^{*}$ & .439 & .006 \\
\hline FERV & -.167 & .426 & .450 & 1 & .080 & .317 & -.027 & $.761^{* *}$ & .203 & $.826^{* *}$ & .501 & $.713^{* *}$ & $.654^{*}$ & .068 \\
\hline URV & .144 & -.162 & -.264 & .080 & 1 & -.337 & -.497 & .118 & -.452 & -.244 & -.216 & -.368 & -.164 & .376 \\
\hline NFV & -.302 & .390 & .138 & .317 & -.337 & 1 & .070 & .211 & -.045 & .387 & $.745^{* *}$ & .375 & .417 & .052 \\
\hline SPIV & .030 & .102 & .011 & -.027 & -.497 & .070 & 1 & -.370 & .114 & .008 & .266 & .470 & .262 & $-.839^{* *}$ \\
\hline SRV & .010 & .552 & .414 & $.761^{* *}$ & .118 & .211 & -.370 & 1 & .205 & $.777^{* *}$ & .411 & .438 & $.604^{*}$ & .276 \\
\hline MSV & -.089 & -.036 & -.024 & .203 & -.452 & -.045 & .114 & .205 & 1 & .177 & -.146 & .203 & .082 & -.044 \\
\hline DIOV & -.260 & .378 & .475 & $.826^{* *}$ & -.244 & .387 & .008 & $.777^{* *}$ & .177 & 1 & .524 & $.703^{*}$ & $.635^{*}$ & .119 \\
\hline IRV & -.406 & $.763^{* *}$ & .443 & .501 & -.216 & $.745^{* *}$ & .266 & .411 & -.146 & .524 & 1 & $.770^{* *}$ & $.824^{* *}$ & -.079 \\
\hline GDPV & -.444 & $.621^{*}$ & $.588^{*}$ & $.713^{* *}$ & -.368 & .375 & .470 & .438 & .203 & $.703^{*}$ & $.770^{* *}$ & 1 & $.810^{* *}$ & -.220 \\
\hline IRDV & -.252 & $.767^{* *}$ & .439 & $.654^{*}$ & -.164 & .417 & .262 & $.604^{*}$ & .082 & $.635^{*}$ & $.824^{* *}$ & $.810^{* *}$ & 1 & -.164 \\
\hline DDEV & -.535 & -.177 & .006 & .068 & .376 & .052 & -.539 & .276 & -.044 & .119 & -.079 & -.220 & -.164 & 1 \\
\hline
\end{tabular}

Footnote $1: * *: \mathrm{P}<0.01^{*}: \mathrm{P}<0.05$

Footnote2: Number of samples $=13$ 
Table 2. The regression model summary

\begin{tabular}{|l|l|l|l|}
\hline $\mathrm{R}$ & R Square & Adjusted R Square & Std. Error of the Estimate \\
\hline 0.979 & 0.958 & 0.844 & 0.010503275164074 \\
\hline
\end{tabular}

Table 3. The VIF values

\begin{tabular}{|l|l|l|}
\hline Variable & Tolerance & VIF \\
\hline FDIV & 0.431 & 2.318 \\
\hline TSV & 0.553 & 1.807 \\
\hline URV & 0.358 & 2.791 \\
\hline NFV & 0.581 & 1.721 \\
\hline SPIV & 0.226 & 4.428 \\
\hline SRV & 0.352 & 2.844 \\
\hline MSV & 0.494 & 2.024 \\
\hline DDEV & 0.249 & 4.014 \\
\hline
\end{tabular}

Table 4. The standardized $\beta$ value and relative weight of each macroeconomic variable

\begin{tabular}{|l|l|l|l|l|l|}
\hline Variables & Standardized $\beta$ & Relative weight & Variables & Standardized $\beta$ & Relative weight \\
\hline FDIV & -0.604 & 0.3894 & URV & 0.362 & 0,2029 \\
\hline TSV & -0.034 & 0.022 & NFV & 0.644 & 0.361 \\
\hline SPIV & -0.381 & 0.2456 & MSV & 0.247 & 0.1385 \\
\hline SRV & -0.532 & 0.343 & DDEV & 0.531 & 0.2976 \\
\hline
\end{tabular}

* The FDIV, TSV, SPIV, and SRV will make the currency appreciate, while the URV, NFV, MSV, and DDEV will make it depreciate.

Table 5.The weighted sum ofthe macroeconomic variables with positive effect

\begin{tabular}{|l|l|l|l|l|}
\hline Variables & Relative weight & Minimum & Average & Maximum \\
\hline URV & 0,2029 & -0.1 & 0.0298 & 0.1612 \\
\hline MSV & 0.1385 & 0.0906 & 0.0216 & 0.2210 \\
\hline DDEV & 0.2976 & -0.4358 & 0.0122 & 0.3534 \\
\hline NFV & 0.361 & -1.8195 & 0.0193 & 0.9266 \\
\hline Weighted sum & & -0.7943 & 0.0207 & 0.5029 \\
\hline Adjusting multiplier & & 8.3076 & 8.3076 & 8.3076 \\
\hline Adjusted weighted sum & -6.5985 & 0.1722 & 4.1786 \\
\hline
\end{tabular}

Table 6.The weighted sum ofthe macroeconomic variables which have negative effects onthe growth rate of exchange rate

\begin{tabular}{|l|l|l|l|l|}
\hline Variables & Relative weight & Minimum & Average & Maximum \\
\hline TSV & 0.022 & -0.3264 & 0.3508 & 2.2917 \\
\hline SPIV & 0.2456 & -0.6539 & 0.2517 & 1.3043 \\
\hline SRV & 0.343 & -0.0512 & 0.0178 & 0.6139 \\
\hline FDIV & 0.3894 & -0.1131 & 0.0684 & 0.2358 \\
\hline Weighted sum & & -0.2294 & 0.1722 & 0.6731 \\
\hline Adjusting multiplier & & 1 & 1 & 1 \\
\hline Adjusted weighted sum & -0.2294 & 0.1722 & 0.6731 \\
\hline
\end{tabular}


Table 7. The standardized values for the total magnitude of appreciation and depreciation

\begin{tabular}{|l|l|l|l|}
\hline Variables & depreciation & average & appreciation \\
\hline $\begin{array}{l}\text { Adjusted weighted sum for the } \\
\text { Variables with positive effects }\end{array}$ & 4.1786 & 0.1722 & -6.5985 \\
\hline $\begin{array}{l}\text { Adjusted weighted sum for the } \\
\text { Variables with negative effects }\end{array}$ & -0.2294 & 0.1722 & 0.6731 \\
\hline Total magnitude of appreciation and depreciation & 4.4080 & 0 & -7.2717 \\
\hline Standardized Value & 0.5184 & & -0.8551 \\
\hline
\end{tabular}

Table 8.The Numbers in Real Options Model

\begin{tabular}{|c|c|c|c|}
\hline Variables & Means & Sources & Value \\
\hline$\alpha$ & The average growth rate of accumulated foreign exchange reserve & Empiricism & 0.2906 \\
\hline$\sigma$ & $\begin{array}{l}\text { The volatility of growth rate of accumulated foreign exchange } \\
\text { reserve }\end{array}$ & Empiricism & 0.1459 \\
\hline$\lambda$ & The frequency of government intervention & Assumption & 0.25 \\
\hline$\xi$ & The intensity for sudden events & Assumption & \pm 01 \\
\hline$R_{\mathbb{R}}$ & $\begin{array}{l}\text { The magnitude of macroeconomic variables with positive effect on } \\
\text { the growth rate of exchange rate }\end{array}$ & Regression & -0.001 \\
\hline$R_{\mathbb{R}}$ & $\begin{array}{l}\text { The magnitude of macroeconomic variables with negative effect on } \\
\text { the growth rate of exchange rate }\end{array}$ & Regression & -0.035 \\
\hline$a_{1}$ & The slope of $g$ to the growth rate of exchange rate & $\begin{array}{l}\text { Regression } \\
\text { and } \\
\text { Assumption }\end{array}$ & 0.0002 \\
\hline$a_{2}$ & The slope of $g$ to the growth rate of exchange rate & $\begin{array}{l}\text { Regression } \\
\text { and } \\
\text { Assumption }\end{array}$ & -0.1482 \\
\hline$b_{1}$ & $\begin{array}{l}\text { The constant of } g \text { with positive effect on the growth rate of } \\
\text { exchange rate }\end{array}$ & $\begin{array}{l}\text { Regression } \\
\text { and } \\
\text { Assumption }\end{array}$ & -0.0001 \\
\hline$b_{2}$ & $\begin{array}{l}\text { The constant of } g \text { with negative effect on the growth rate of } \\
\text { exchange rate }\end{array}$ & $\begin{array}{l}\text { Regression } \\
\text { and } \\
\text { Assumption }\end{array}$ & 0.018 \\
\hline
\end{tabular}

